doi:10.7592/FEJF2012.50.pakalns

\title{
VISUAL JOKES ABOUT CHRISTMAS AND SANTA CLAUS ON THE INTERNET - WHY AND WHY NOT?
}

\author{
Guntis Pakalns
}

\begin{abstract}
This article analyses a collection of Christmas-related images and video clips found on the Internet. The author started collecting this material in 2005, since that time the material in the form of a PowerPoint presentation has been shown to diverse audiences discussing the context (mainly from the perspective of a folklore researcher) while observing the reaction of the audience.

The central part of the article is devoted to a brief overview of the most characteristic groups of the jokes (with links to the images, video and descriptions of the traditions): Santa Claus as the bringer of presents, his trip from the northland and his friend Rudolph the Red-Nosed Reindeer, arrival through the chimney, different other persons wearing Santa's hat (politicians, terrorists, women, animals, etc.), Santa's sexuality, drunken Santa, Santa murdered/killed, etc. In addition, the regional version - Ded Moroz and Snegurochka (Father Frost and the Snowgirl) - is discussed here. Parodies related to the topic - the Christmas tree, snowmen and figures made of snow, elves, angels, Chinese horoscope's "animals of the year".

Some hypotheses regarding the differences, functions, selection and perception of the worldwide available jokes in different social situations (western and post-Soviet world) are put forward, also considering social groups and situations, the time before and after Christmas. Why would people need such jokes? An attempt is made to explain it by different "levels of joking" - starting with "simply jokes" with their specific context in the tradition of the particular subject matter and the carnival-like sense of the reversed world (also used by the traders, making the originally rather eerie Santa Claus look like a friendly joker in the "shopping mythology") and jokes as a kind of psychological self-defence - trying to compensate, by way of irony and black humour, for the rapidly changing and excessive tediousness, seriousness, sacralisation, or right the opposite - secularisation, commercialisation of the mass media imposed Christmas traditions and the holiday stress.
\end{abstract}

Key words: Christmas, Ded Moroz, Internet folklore, Internet humour, modern myths, parodies, Santa Claus

At the end of 2005 The Club of Emeritus Scholars of the Latvian Academy of Sciences invited me to lecture about Christmas. A year earlier they had heard a lecture by an outstanding professor on the Latvian traditional Yuletide. I did 
not want to sound repetitive, besides I was not confident that I would be able to maintain a serious facial expression while talking about how clever the "ancient Latvian" was while beautifully celebrating this festivity in the historically nondifferentiated distant past - I assumed that this was expected on the level of stereotypes from a folklorist. But I chose to view the topic from the "other end" - how this festivity continues its life in modern culture, while simultaneously taking the opportunity to inform colleagues from other branches of science and scholarship about the changes in folklore study in modern days. ${ }^{1}$

I arranged a bulk of funny and comic images, video clips and PowerPoint presentations that I (just the same as many others) had collected, over time on my computer's hard disk drive, by theme. Supplemented them with similar materials from the Internet - all I could find with little effort. I arranged this material by topics and chapters, placing variants side by side and following the sequence of activities by placement of the aforementioned chapters, thus creating some "plot" within reasonable limits - similarly to the practice found in folklore publications, including also the academic edition of Latvian folksongs. I went there and presented the audience with the result of my efforts, briefly commenting on the images within the limits of my understanding.

When I finished my lecture the audience consisting of some 100 scientists of honourable age was strangely silent... They asked me no questions and did not discuss the subject matter, neither did they object nor rebuke my approach. It seemed that many of them were thinking something like this: "When we were young the world had much better morals!" In any case, what I presented was not the romantic "Christmas story"" that probably was expected (Figs. 1-2).

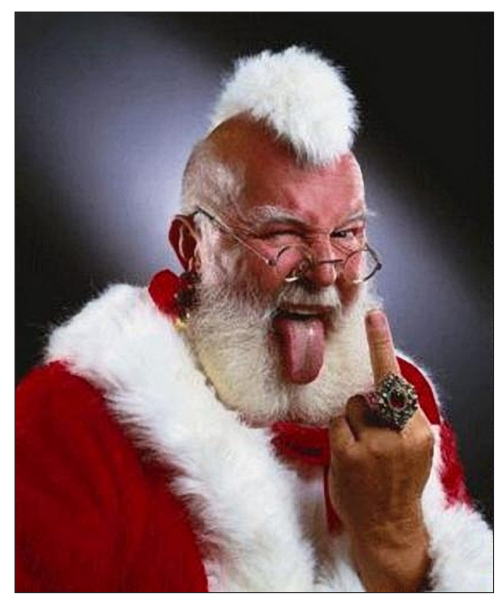

Figure 1. Santa Claus - a punk. (Source: http: / / www.fotolog.com / alantijuca /37189946 /)

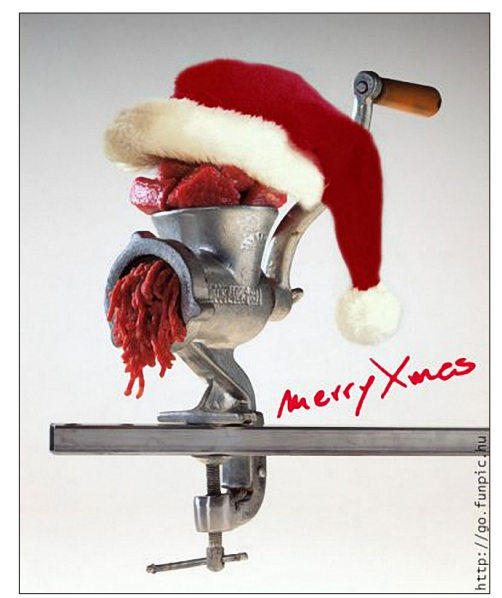

Figure 2. Merry Xmas! (Source: http: / / www. funpic. hu/en/categories / santa-x-mas/25024_ merry-xmas?142) 
I have later updated the presentation adding new and current material, including more "positive" and "beautiful" examples, which still seemed rather flat and boring in comparison to jokes and humour. But the basic structure of that PowerPoint presentation was preserved. Mostly around the turn of the year I have presented it to different audiences, e. g. older and younger folklore enthusiasts, leaders of folklore groups, students of vocational schools, anthropology students and lecturers, my colleagues at the Archives of Latvian Folklore, etc. The most extensive version contains more than 830 slides ( $c a$ 1,100 still images, some 20 video clips and 9 included PowerPoint presentations) with a nearly 3-hour-long lecture, while the shortest - ca 207 slides (318 still images, 8 video clips) and a duration of slightly more than 20 minutes. ${ }^{3}$ During these presentations I not only demonstrate the jokes, but also, depending upon the overall planned length and the interests of the audience, provide some insight into different cultural, historical, social and functional contexts of the images, telling the history of Christmas traditions and symbols - people are surprised at finding many traditions considered age-old being actually rather recent and significantly changed over the last decades.

I have recorded nearly all of these lectures, and the recordings provide material for analysis showing: 1) how very different my comments and topics of conversation can be though dealing with generally the same sequence of images - and this does not only depend on the composition and knowledge of the particular audience (dealing more with either the history of Christmas traditions or the Internet, humour, folklore or mythology - depending on the extent to which these notions need explanation in every particular setting), but also the time of the year (the closer to Christmas, the more carefully one has to be with such jokes); 2) that the reaction of different audiences is also different - laughter, or the very opposite - silence, protests and questions. Although I have tried to be scholarly considerate in my choice of material and comments, I still have a feeling that there is "something wrong" with this collection and its comments - that the critical attitude of the audiences is soundly based. Notwithstanding this general feeling I cannot find anything particular triggering the attitude - is it the material itself, the selection criteria, maybe even the Internet as such, or some problems of personal experience and attitude (I am one of those who "do not love Christmas"; why? - look for some hints at the end of this article). This is also one of the reasons why I had not yet prepared a published version of this presentation. The second such reason is the visual material, which is easier shown than described verbally. Though publication is generally considered the main outcome in scholarship, in this case it appears to be just a secondary one - the primary being the very collection and its different performances as author's (lecturer's and scholar's) communication with every 
particular audience. One more hindrance - the huge amount of material, difficult to be kept in any perspective, and still dynamically growing; also - there are many Christmas-related topics, thus only touched upon, while many are developing into an object of separate study.

It is possible that the cause for the perplexity and indignation of the audience was a particular group of Internet folklore ${ }^{4}$ that could be characterised as ironic, parodying, "dark" and/or aggressive, even destructive. My study deals with this particular group (and not Christmas in general!).

I usually begin by showing several rather typical and popular video clips, the context of which is tried to be found and understood during my performance. Four examples:

1. Santa is sitting in a toilet, (the activities are illustrated by impressive background noises); he notices that he is out of toilet paper. With his pants still down he jumps to the next room, where a huge pile of letters to Santa can be found. He chooses one and returns to the seat reading it. There is constant loud laughter in the background. The clip ends with an advertisement of a clothing store urging to go shopping and not write to Santa. ${ }^{5}$

2. Christmas evening in a family - a candle is lit on the tree, the Grandpa opens a song book, children dressed in stylised national costumes start playing "Silent Night..." on a recorder, guitar and a keyboard; it sounds somewhat awkward, with false notes. Mother listens to it with concern but also proudly, Grandpa falls asleep, father picks up his beer... At this moment the children turn to some wild rock'n'roll music, and just like at some concerts the guitar is smashed, the girl jumps up the Christmas tree and tumbles it with a shriek. Grandpa wakes up and looks at all the activities quite approving. The clip ends with a short ad, apparently music industry related. ${ }^{6}$

3. Seemingly, a home video, filmed with a hand-held camera: a child unpacks his gift - a light-sabre resembling that seen in "Star Wars"; he sways it around and inadvertently cuts Grandma in half, then the lamp comes down, after which the screen is filled with noise - the camera has been hit... ${ }^{7}$

4. On a football field there are 11 women, seen from behind. A simple animation moves their buttocks, so that they appear to be "playing" the Christmas song "Jingle bells" in this way. ${ }^{8}$ 
The problem remains: people laugh at these jokes, forward them to others, but become infuriated seeing them collected in larger numbers and in a public environment. Should a researcher of folklore and culture ignore them or still study? Is folkloristics capable of providing any explanation? What are the jokes about? What do these jokes say about social processes and Christmas traditions?

In order to understand (or interpret), let us view several contexts including the following: 1) the Internet as a "natural" communication environment (similar to oral storytelling two or three centuries ago, or a newspaper a hundred years) and the Internet lore; 2) Santa as an important image of modern mythology - becoming more and more international, but still with national or local features; 3 ) commercialisation of Christmas, that has possibly made some modern Christmas traditions "aggressive" towards people, creating more stress situations (growing volumes of shopping, adaptation to mass media stereotypes) and obtrusively offering in the public space trivialised and secularised symbols of this festivity.

Some information regarding the collected material: my collection consists of approximately 3,000 files, mainly still images (though including some animated), PowerPoint presentations and video clips. The method of collection: received by e-mail (I asked acquaintances and students to send them to me, some of the most diligent were those working in state institutions) or found on the Internet. Many of the files were received several times, found on numerous sites (frequently only the logo of the site had been added, with no indication of origin), thus it is becoming increasingly difficult to find anything thematically new or any new content - this might attest to the collection being representative.

Initially I was interested exclusively in the material to be found in the Latvian environment and Latvian websites, but soon I became aware that it is a fragment from a much larger multinational tradition. (Some small national features can be found, but, omitting the few local jokes and particular wordplay, there are regional traits, such as "to the west" or "to the east" of the Baltic States, i.e. jokes in Western Europe and the USA, and jokes in the former USSR territory. And a second aspect - what is considered funny, interesting and agreeable by people of different groups, nations). There are sites that have images related to Christmas, Santa or the New Year placed separately. ${ }^{9}$ But a great many images can be found within other collections - while collecting the material I spent days and weeks sitting still and browsing different archives of jokes and images, copying from those what I found useful, making sure that my "field-work" on the Internet is no less physically demanding than visiting informants by dirt roads in faraway, secluded places. At the time, I was not yet aware of such search tools as Google Images; however, several of the largest sites have accumulated archives from the last 5-10 and more years, 
facilitating search. I used not only the anonymous images, but also caricatures by known authors that were freely available on the Internet and "played" with the traditional topics. ${ }^{10}$

Placing the images in particular chapters and positions of my presentation I created my own "Christmas story" which, in a way, is also a tradition, although usually, such sequences do not exceed 10-30 images. For the context I also collected texts (anecdotes, funny stories, proverbs and quotes, etc.). Quite frequently such texts are combined with audiovisual material (PowerPoint presentations with music, images and some aphorism, chain letters, visualisations of written texts, etc.), so there are no strict limits. One can observe a tendency "from the text to the visual" - the latter can be more readily and conveniently perceived, requires less effort. Thus, unlike during the early days of the Internet when only small data amounts could be sent, the images and videos have become much more popular nowadays. Yet as with all things in folklore only a small part of the "folk creation" has become popular. It was more difficult to document the online games where, e.g., Santa is the hero (or just in the function of the ball), as well as earlier only online viewable flash videos (e.g. "the dancing reindeer"11), or personalised greeting cards ${ }^{12}$. Naturally, it is not possible to cover all of these joke genres, therefore I have focused on images. Each of this genres covers a range of topics that is either partially common or overlapping, but each of those has more or less pronounced specifics determined by both their history and technology.

Not delving into theory and avoiding quoting particular authors I shall briefly remind the reader of some issues regarding this material from the folklorist's perspective.

Naturally, this is not pure folklore and nothing else but folklore, still it is an object of interest to the researchers of folklore and other culture research spheres. They possess the characteristics of traditional folklore: 1) tradition (in form, content, function, genre, images, performance situation, etc.); 2) variation of the traditional themes; 3) collectivism, anonymity, popularity (no authors known, people readily "retell" - forward, "quote" in different situations, create private and public collections); 4) these are used by groups forming common identity; 5) reaction to power, the ruling, the right ideology (alternative culture), etc.

The Internet offers new opportunities to meet the ancient need of the people: 1) communication - to exchange messages, find similarly oriented individuals, form communities with an identity (communication on the Internet is closer to oral tradition than the printed texts, as there is the possibility of feedback - evaluation, comments, forwarding, developing similar material, etc.); 2) fun - watch, compose and retell jokes; 3) listening to stories, watching images and 
events, feeling informed; 4) secretly watching and doing what is considered indecent.

Santa Claus (Father Christmas, Дед Мороз, Weihnachtsmann, etc. - the names in different traditions are not the same but the origins are at least partly common) is an outstanding personage of modern mythology, not only for children. As is known, this image has a lengthy history, but the image still in use was formed in the 19th century, in the mass media environment of the time (press), combining elements from different cultures. It continues to develop dynamically in the 20th century. Many of the elements of this image can be clearly dated, but this is deliberately forgotten. Santa Claus has its own myth of ancient origins, its own image (is it the archetype of the wise old man, father?), he dwells in the mythical and the real space, has his specific attributes (beard, the red coat, bag of presents), helpers and functions. It is the main personification of Christmas in modern times, widely recognised, maintained and publicised by mass media, present in different cultural and traditional structures. ${ }^{13}$

If in earlier times he was frequently pictured as a harsh man with a rod, punishing the disobedient children, then in modern times his main task is bringing gifts (this theme is closely related to industrialisation when gifts became increasingly easier to produce and they had to be sold, thus their religious symbolism was transformed). The closer to the present day, the more pronounced are the features of a trickster, that probably are related to the commercialisation of the image - a jolly and friendly humorous image promotes shopping during the pre-holiday period. (Entering the name Santa Claus, in the Google Images or other image search engines would return results showing him as something comical, but definitely friendly, smiling and clearly joyous.) Santa Claus is an important image in shopping mythology, for instance: 1) as a commercial brand - personification of a gift-shopping-related festival; 2) letters to Santa Claus as lists of gifts; 3) travelling during the festival and to the dwelling place of Santa Claus in Lapland; ${ }^{14} 4$ ) greeting cards, music, films, concerts; 5) jobs for his impersonators. All these trades involve significant financial outlay. Christmas shopping in many countries is the last chance to improve the year's economic figures. Therefore the already folklorised phrase is also true in regard to him: "If there was none such, then he had to be invented."

By the way: what could be the conclusions if some centuries from now a research of the materials on Santa Claus preserved from our day was conducted the way we study ancient Latvian deities - without the knowledge of the cultural context for the texts and images and their situational application? Would it be possible by the images alone, without the aforementioned context to discern which of the character's features are meant "seriously" and which - as comical, ironic, parodying some particular cultural elements or merely insignificant? 
What is this Santa like, judging him by the visual jokes collected on the Internet starting in 2005?

Verbally describing the images (which cannot be shown to the readers of the present article, see previously and further indicated URLs), we can briefly discuss the parodies on several most popular topics regarding Santa and the Christmas "myth" - how these are reflected in the visual part of the Internet folklore. As already known only that can be parodied which is widely, generally known, otherwise the parody will not be recognised and understood. For the sake of simplicity I will ignore the different "national variants" of Santa (Weihnachtsmann, Ziemassvētku vecītis, Ded Moroz, St. Nikolaus, etc.), as the internationally more readily available Internet folklore in most cases allows us to view this character as generally homogeneous, without particularly pronounced and specific "national characteristics".

One or many? Despite the "official myth" (that Santa lives in the North alone or together with his wife, who is the only female in the dwelling - and makes gifts together with his elves), many of the images depict together tens, hundreds and even thousands of similarly dressed performers of the task. They participate in the Christmas race, go skiing and - of course! - go shopping in supermarkets, are seen in store decorations. Video clips show many Santas being trained in an army camp, ${ }^{15}$ etc. In similar costumes, with the difference being the much less amount of cloth used - those are the generally pretty female representatives of the trade. Still, in most jokes Santa is alone.

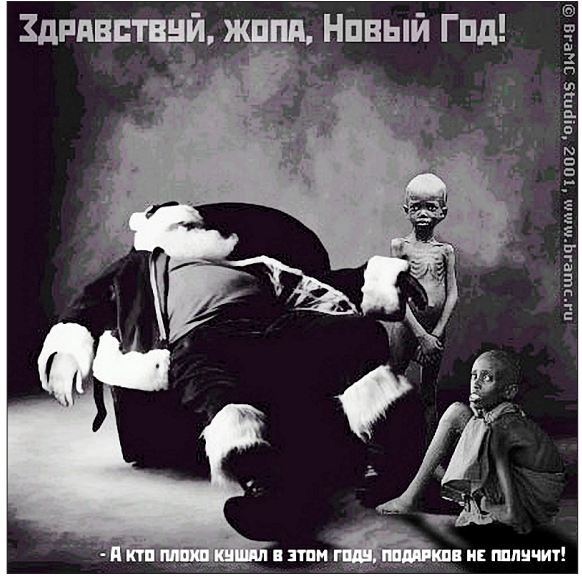

Figure 3. Those who have not eaten properly will receive no presents! (Source: http: / / www. bramc.ru/cgi-bin /page.pl?docid=112)

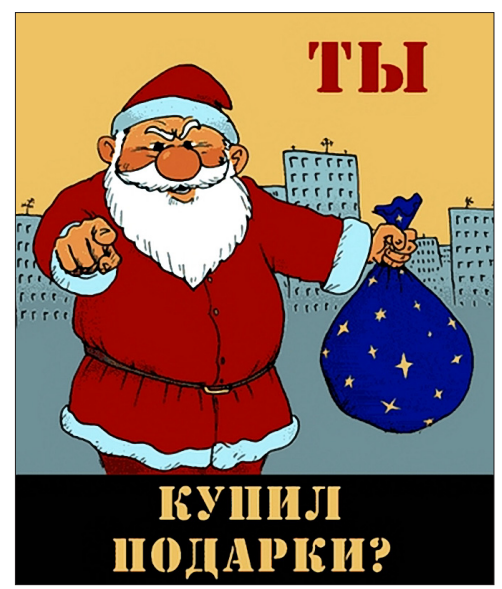

Figure 4. Have you bought the presents? (Source: http: / / www.cruzo.net/kartinki / novogodnie/a-ty-kupil-podarki.html) 
Santa as bringer of gifts. His too heavy bag of gifts is frequently treated, along with its non-traditional content (weapons - the "toys" for adults), and the way of the bag's delivery. There are jokes related to the over-lengthy list of the required gifts, to the production of those gifts or their purchase, about the idea that every one seeing Santa has the right to demand a gift (even when on the potty...), regarding the phrase that only the children who have eaten all their food will receive those gifts (Figs. 3-4). (Within the framework of this topic it is possible to tell the history of Christmas gifts, which has seen dramatic changes over the course of time, as well as explain the ethnography of gift-giving as such.)

Santa arrives from afar - thus from abroad! The parodies play on the situations that are not included in the fairy-tale or "myth" on the arrival from far away - what happens when Santa Klaus meets border guards (Klaus - obviously a German!), customs officials (confiscating gifts as illegal merchandise), how he is incarcerated for illegal border crossing or unlicensed night flights.

Rudolf the Reindeer is not only show as the puller of Santa's sleigh, but also as a friend of his and a man-like ally. ${ }^{16}$ The parodies deal with the different problems that may result in the modern view from the driving of sleigh pulled by reindeer in general or specifically Rudolf - no safety belts, braking at crossings, technical condition of the road and the vehicle's lights (Rudolf's red nose), speeding, ${ }^{17}$ meeting road police or thieves stealing from the sleigh, etc. A wide range of parodies are related to the flight of the sleigh - it is visible in allegedly documentary photographs taken through an aircraft's window, the sleigh caught by a plane's wing, the sleigh crashing into an UFO or different buildings, including a parody on 11 September in the USA - Santa crashing into Twin Towers (Figs. 5-6). It is said that Rudolf can only fly because of his drug addiction. A proof of the sleigh

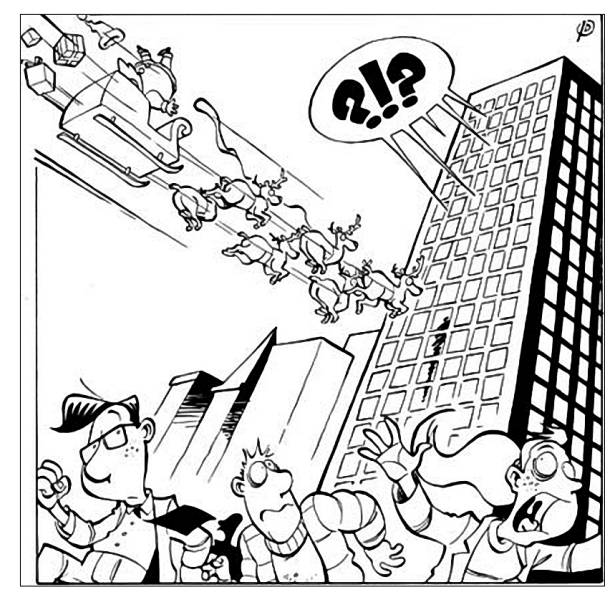

Figure 5. Christmas 2001. (Source: http:// www.funpic.hu/en/categories/santa-xmas/9678_picture)

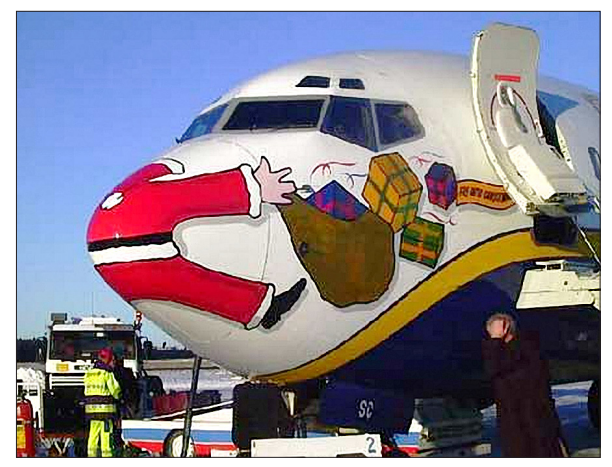

Figure 6. Santa Claus hits a plane? (Source: http: / / www.esche-world.de /lustigebilder / weihnachten / crash-mit-flugzeug-1280.html) 


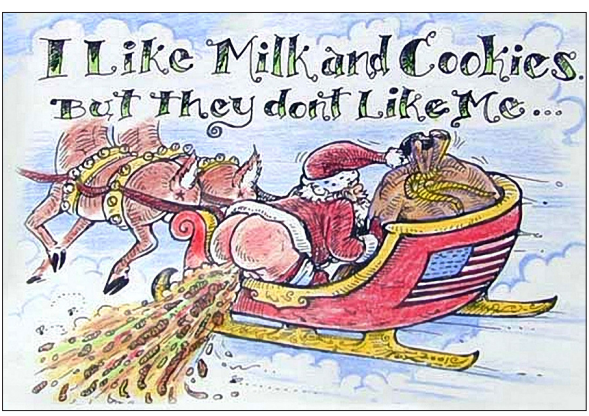

Figure 7. I like milk and cookies, but... (Source: http:/ / www.funpic.hu/en / categories / santa-x-mas /9610_picture) having flown over a house is reindeer droppings on its roof. But these can also be a result of Santa overeating milk and cookies left for him in every house (Fig. 7). As they are together most of the time the caricatures also deal with the relationship of Santa and Rudolf as a close one of two men, there is also a clip showing Santa buying a rubber doll from a sex shop - an inflatable reindeer ${ }^{18}$ (Fig. 8). Different animations show reindeer singing and/or dancing happily. Those who feel bored by such happy singing can choose a clip where a reindeer sings "Silent Night" in the voice and appearance of a drunk. ${ }^{19}$ Depending upon the "animal of the year", Santa's sleigh can also be pulled by a dragon, bull, monkey, rooster, etc.

Hereinafter it is obvious that in frequent occasions, the main method of joke-making is desecration of the beautiful and generally known "myth" of Santa - what makes up the very core of the Santa's story both in children's literature (and partly also business mythology) is being ridiculed, trivialised, placed in mundane, unlikely or "worst possible" situations. Another way, more belonging with official culture, is the aestheticising and modernisation of the myth, formally adapting it for the modern world.

An example: Santa's other vehicles. This is dominated by "simply nice pictures" - of Santa with his huge bag on his back riding a motorbike, a motor

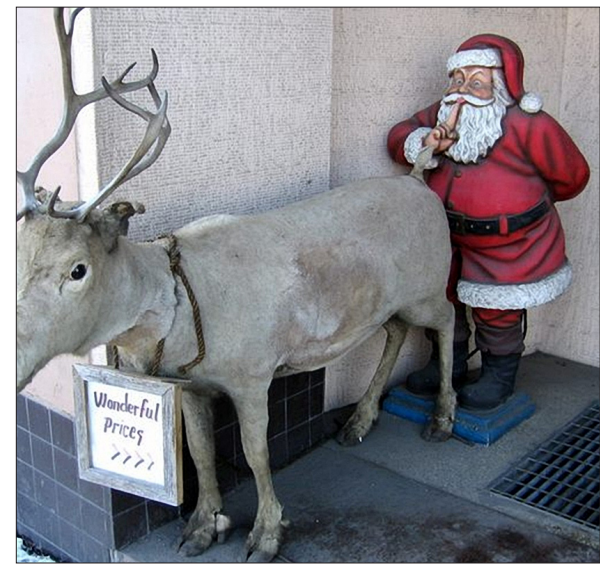

Figure 8. Santa Claus - a too close friend of Rudolph? (Source: http: / / www.cruzo.net / kartinki/novogodnie /xitryj-santa.html)

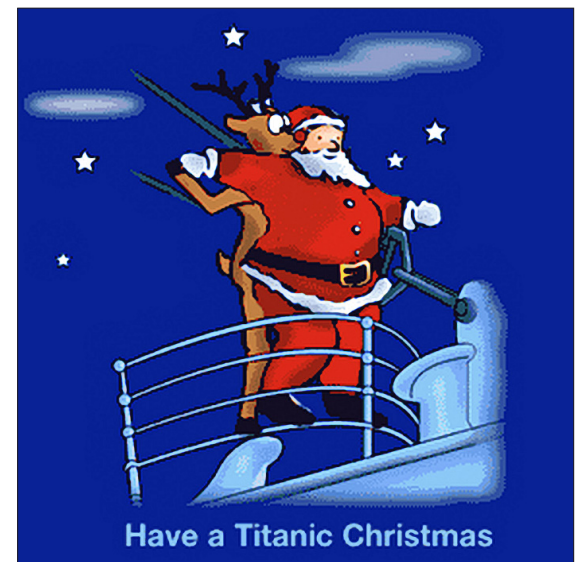

Figure 9. Have a Titanic Christmas! (Source: http: / / www.funpic. hu / en / categories / santa-xmas/9439_on-the-titanic) 
sleigh, driving a jeep, flying a plane, a rocket, on board a ship, arriving with diving equipment or a parachute. At the same time, the alternative cultures feature parodies of this topic of vehicles - Santa and Rudolf on the bow of "Titanic" (Fig. 9), a bike shaped as a reindeer etc.

Did you expect Ded Moroz? Jokes and parodies, of course, are interested in the unusual and unexpected. This is also true regarding the arrival of Santa - those at home are unprepared and taken by surprise, the children would not leave the telly. Santa falls into some trap set by the owner of the house to catch thieves, or even gets shot because he was entering through the chimney and taken for a thief. In the Russian-speaking environment the caricatures also employ the play of meanings: in Russian jargon 'to order' (zakazivatj) also means 'order a murder of...'.

Entrance through fireplace chimney as obviously illogical and incredible is very much employed in this type of material - Santa, of course, is too fat, and therefore gets stuck. The reindeer try to save him or lose all hope and leave without him. Other images of Santa: he sits on the chimney with his pants down, like on a toilet seat. Or how icicles are formed - romantic children faces watch through the window yellowish icicles growing, while they do not see that these grow from Santa and Rudolf urinating. In case Santa manages to get through the chimney all soiled black in soot, it is not a victory for him yet: he inadvertently kills the cat sleeping by the fireplace, is taken for a thief, or he arrives in a hangout of drug addicts, catches a naked couple on a coach, is met by a dangerous dog, etc. The parodies of sexual nature also belong here: a girl or a woman offers herself, instead of milk and cookies, while lying naked by the fireplace.

The story of the chimney is also employed in a very popular animation - a parody of the tale of three piglets. ${ }^{20}$ Accompanied by dynamic and exactly illustrative music the piglets are carrying the Christmas tree, chased by the Big Bad Wolf. They manage to reach their house. The Wolf is trying to break the door, barricaded by the piglets using everything available (while the window is actually left accessible). Then the Wolf leaves. In a moment heavy footsteps are heard, someone is attempting to enter through the chimney. The piglets have a quick solution, taking off the lid of a pot and the intruder falls in and the fire is started in the stove. When the pot is served on the table Santa's hat and a boot along with some gifts are floating on top. The closing scene - in the yard the sleigh with reindeer stands waiting. The fact that many have already seen this film means that it is distributed like folklore - it is "told" (forwarded).

Santa's hat. There is a rich cluster of world wide web-distributed visual parodies showing different characters wearing Santa's hat. (As to my memory, in the Soviet times this hat was the exclusive attribute of Ded Moroz, no-one 
else was allowed to wear it. This tradition changed in the $1990 \mathrm{~s}$, when the supermarkets started offering such hats for a rather low price - I had a difficulty accepting that in the West this hat has a different function and meaning: by wearing it we just participate in the festival, their "carnival". The caricatures depict as Santa (most often marking by the hat alone, seldom - the full costume) both the well-known politicians (sometimes with the bag - as "gift bringers", one's promising "gifts" in the new year) and terrorists - making people remember terrorism as a global modern problem, that can influence the future of the whole world in the next year. Santa can also be transformed as a horrible image of some computer game. Computer technologies allow for simple and quick transformations of images, therefore the result depends more on the taste of the creator (and those forwarding the image), not the technology.

Related to the previous topic - Santa is dead: hanged in a toilet (Fig. 10), caught by the helicopter blades, torn apart by dogs or polar bears, an allegedly documentary photograph showing both Santa and his reindeer shot by a hunter, etc. Wordplay used because of the similarity in Russian: Ded Moroz - Dead Moroz. Crucified - due to a mix up with Jesus or for some reason substituting the latter ${ }^{21}$ (Fig. 11). An image of a crying boy and the tombstone of Santa. ${ }^{22}$ This displays another way of demythologisation - to pronounce someone dead (does therefore the myth die along with the character?). However, this motif is related to the image of Ded Moroz as personification of the old year, better known on the territory of the former USSR. The New Year was personified as a boy turning into an old man in a year's time, then either driven out or "killed" by the next New Year. If there is a will one can trace the so-called transition

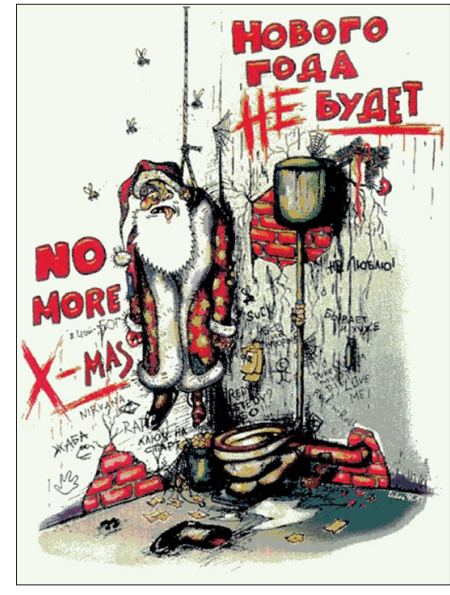

Figure 10. There will be no New Year! (Source: http: / joki.oho.lv/default. php?grupaid=1\&bid=1923)

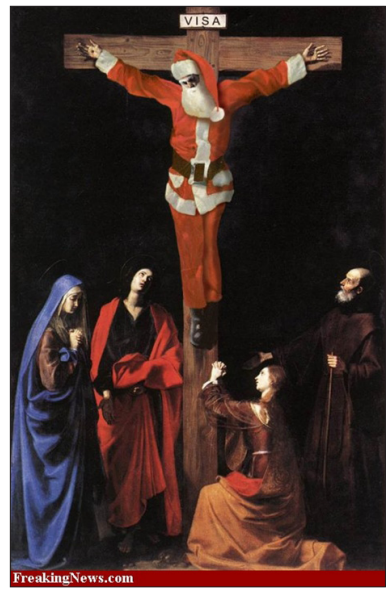

Figure 11. Santa Crucified. (Source: http:// www.freakingnews.com/Santa-Crucified-Pictures-42109.asp) 
ritual as the basis of this - the old must be symbolically killed in order to access the new.

Images of animals wearing Santa's hat are extremely popular, the reindeer horns being seldom employed in this function; one will also find animals around a decorated Christmas tree, mostly cats and dogs. The same hats, horns and angel wings are used as a costume when photographing small children (probably reference to child Jesus, appearing in these parodies nearly unexpectedly seldom). This range is dominated by the "nice", not comic images. Still, the most popular comic image is that of a dog "leaving poo" by the tree and gift boxes.

Unlike children and animals, the adults put on this hat fully consciously. Probably the most numerous images, though only partially related to parodies and jokes, while having more in common with sexual and pornographic images, are the ones depicting half-naked or nearly naked people only covered by some Santa's attribute or showing a decorated tree in the background. The jokes dwell on the issue whether a woman can be a Christmas gift herself, or whether she can get her gift without getting laid (Figs. 12-13). Woman's breasts are compared to tree decorations, "Merry Christmas!" is written on the naked body parts, etc. Photographs taken at Christmas and New Year parties display this approach.

In this context Santa's sexuality is also being discussed (one more aspect of demythologisation and "tough not" for the hypothetical over-serious researchers of the 21st century mythology in the near future). He is paging through sex magazines, pictured with one or more half-naked girls and different indecent situations. Also as an exhibitionist "coat opener" (actually showing a watch

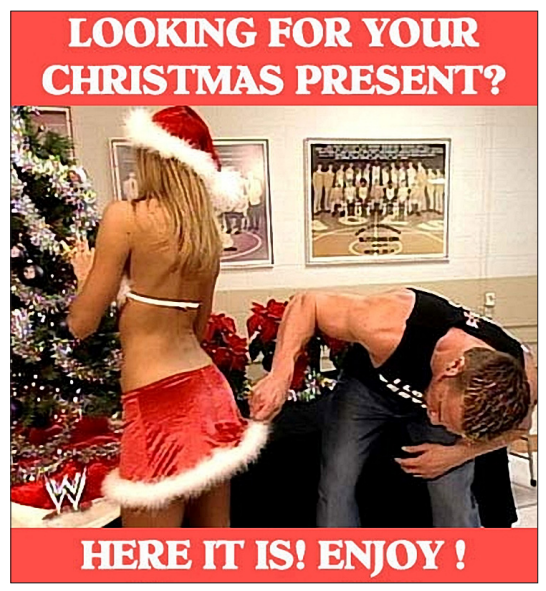

Figure 12. Looking for your Christmas Present? (Source: http: / / www.funpic.hu/en/categories / santa-x-mas /9703_picture)

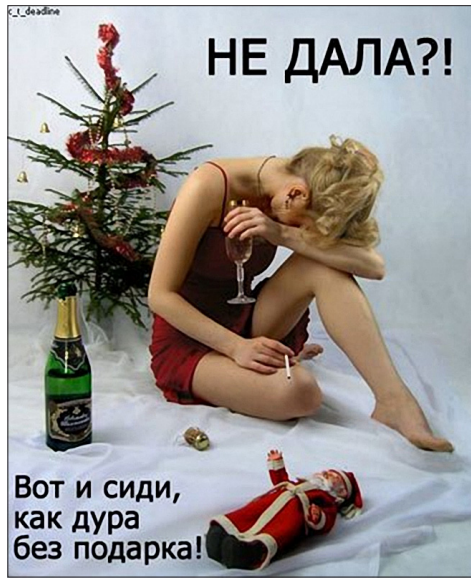

Figure 13. No sex - no gifts! (Source: http: / / www.netlore.ru/novogodnee) 
symbolising the passage of time), a sado-masochist (he himself or his host being extremely pleased by the rods brought), in close relationship with Rudolf, or bringing his wife erotic toys styled in Christmas theme. A popular theme is the one wherein Santa is punishing quite grown-up "naughty girls", as well as variations of the type of anecdotes: unexpectedly the husband returns ("Virginia, Santa really does exist!"23), wordplay with sexual hints: "Santa Claus is coming". (Following the protests of female audiences I have substantially reduced this part of my presentation.)

One more way to "compromise Santa" are photographs showing him with one or more children on his lap, but - unlike the traditional happy festive images - the child is scared, cries, and tries to break free. ${ }^{24}$ In connection with the discussed above, also the images of a "big girl" sitting on Santa's lap or Santa holding a child while sitting on a toilet seat also belong here. These images can be interpreted as a response to the widely distributed pictures of an overly "correct" character (Santa or more generally - a positive mythical hero, a politician - with a happy child on his lap).

There is another popular cycle of images: drunk Santa - with a bottle of booze in his hand, answering the call of nature, asleep half-naked, etc. This cycle still emphasises the differences between the "West" and the "East" - if Santa is shown as a jolly person celebrating (from the mythology view-point this is just an indication of ritual use of alcohol at a festival), images of Ded Moroz displaying the captions in Russian emphasise the "harsh reality" of Ded Moroz's position, practically requiring a healthy dose of alcohol in order to maintain sanity, the only problem being that of knowing the limits.

The characters of both Ded Moroz and Snegurochka are usually connected with alcohol. The joke goes that Ded Moroz is a mythological character - when sober. Snegurochka tends to be shown not as the grand-daughter (as in the "nice" texts), ${ }^{25}$ but as a partner, girlfriend (unlike other Santas who usually having male helpers). Ded Moroz needs her because of drunkenness or some other reason he is unable to perform his duties. This shows some relation to the image of the woman in the culture of Soviet times, where she is shown as being stronger than the man, capable of doing all "men's jobs" when the man is not willing or incapable to do them (Figs. 14-15). Another branch of Snegurochka motifs is her strong sexuality, playing

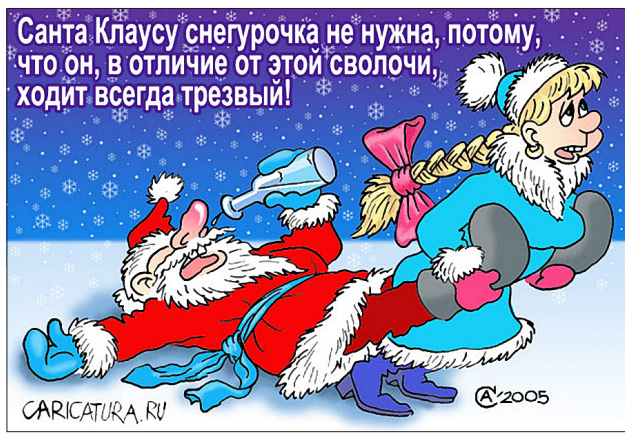

Figure 14. Santa Claus needs no Snegurochka, as he, unlike this bastard, is always sober. (Source: http: / / caricatura.ru/art /Sayenko/url/parad / Sayenko/6296/) 
with her initial coldness and "melting" in warmth.

Some more characters, objects and images are related to Christmas and turn-of-the-year mythology as well as the corresponding jokes. The Christmas tree. (I have noticed that there is a tendency not to believe that it only became popular in present-day Latvia and the surrounding territories around the end of the 19th century and the first half of the 20th - childhood experience tends to take precedence over any facts established by scholars $)^{26}$. Caricatures show different ways the fir tree attempts to avoid being cut down (from the tree's point of view - how nice to be ugly; there is no more terrible festival than Christmas, etc.). "Discreditation" of the tree is popular - people like to publish photographs and drawings showing a small, ugly tree, hanging upside down, decorated using improper objects (Fig. 16), built of empty or full bottles of alcoholic beverages (a very widespread motif) or metal, as well as different foodstuff; a tree vandalised by a cat, a tree falling over, etc. Of course, interest of the people is also attracted by unusual house lighting decorations, using indecent symbols or texts. Also this proves that the Internet joke culture is a secondary one, alternative to traditional culture.

The Snowman is a characteristic part of the winter landscape, ${ }^{27}$ and sometimes also a member of Santa's team. The Internet jokes most

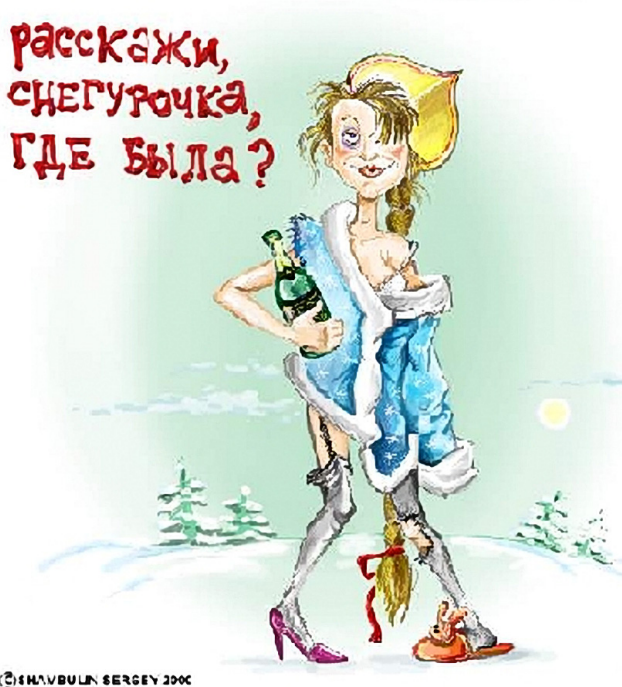

Figure 15. Tell me, Snegurochka, where have you been? (Source: http: / / bayanov.net / funpic/newyear $/$ ? $=09)$ The song gained popularity after being used in the episode 8 of the animation series " $N u$, pogodi!" (“Just wait!”) (1974), see http://www. youtube.com / watch? $v=$ n5DeorAy8lY.

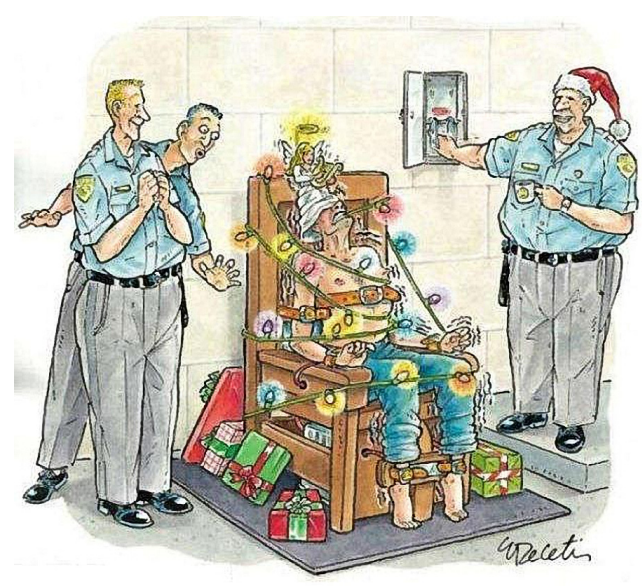

Figure 16. "Christmas tree". (Source: http:// kartinki.smeha.net/novogodnie/113.html) 
frequently deal with the sexuality of these cold snow figures - that carrot is placed not as the nose, but "lower" (Fig. 17), the snow men and snow women having sex (be quick so "the thing" does not melt because of friction), there are photographs of snow figures resembling humans holding bottles of alcohol or in explicitly sexual poses, genitals as huge snow figures. Painted with red the snowmen either are bleeding or become bloodthirsty monsters. Also the snowmen's body transformations are treated, emphasising the difference from the

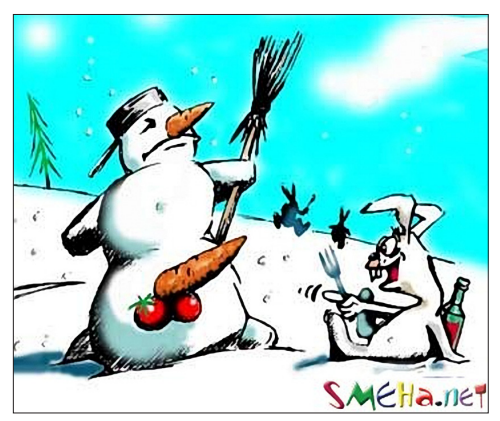

Figure 17. Carrot stuck in the wrong place? (Source: http:/ / kartinki.smeha. net/novogodnie/27.html) humans - snowmen's Kama Sutra, buttocks in place of the head - "a snow MP", fear of melting (a dog peeing on it, a hairdryer as a lethal weapon), a funeral of a snowman (six men carrying a bucket of water), etc. In addition, this displays the intent of creators of these figures (and lovers of the images) to oppose the over-simplified and romanticised culture of childhood and Christmas, making these snow figures "adult", along with the wish to use them for public and anonymous joking about supposedly forbidden topics.

The elves work as producers of gifts at the Santa's workshop (but they also go on strike, are illegal labour, etc.). Unlike their dangerous predecessors in mythology of different European peoples, under the influence of mass media the elves have become jolly kids, but within the further development in the joke culture they have turned into disobedient and naughty "children". In a similar vein angels (as present at the Christian story of Jesus' birth) in the "modern Christmas stories" have become characters not alien to earthly passions.

Along with the above different, other winter-related, images are published - showing extreme amounts of snow or lack thereof, cars stuck in ice or hit by falling icicles, falling skiers, walkers stumbling and falling on ice-covered street, etc. Every year humorous greetings are created, centred on the corresponding animal of the Chinese horoscope, such as rat, pig, etc. And in the conclusion images of Santa returning to his home in the north, pulling the sleigh filled with drunk reindeer, Santa (alone or accompanied by reindeer, elves or girlfriends) on vacation in some southern resort, as well as scenes of celebration from the other side of the equator.

Some conclusions. On 27 December 2005, an interactive question was asked in the Latvian TV1 programme "100 grami kultūras": What Christmas greeting would you prefer? The answers (phone voting, choosing one of three options) were as follows: winter landscape - ca. $40 \%$, religious motif - ca. $20 \%$, a parody on Christmas theme - ca. 40\%. However, regarding the Internet images related to Christmas and Santa Claus, discussed by the author of the present article, 
the proportion of jokes and parodies is (or appears to be) higher. What then is the butt of these jokes associated with Christmas, Santa and the related characters and events? Naturally, these cannot be strictly separated and every particular joke may contain a combination of the following:

1) Plain jokes - exploring and trying the humorous potential and limits for each character and theme within the traditions of humour (similar to those of the related themes: sexuality, "pee and pooh", drunkards, blondes, politicians, the returning husband, etc.). These are dominated by the internal driving force of the joke tradition, not external social contexts.

2) Carnival-like activities - in the period of a threshold moment social values are "turned over". In order to let the New Year come, the old year must be symbolically "killed" (the latter embodied by Santa Claus, Father Christmas, the horoscope animal of the previous year, etc.). Similarly - in order to introduce new, more up-to-date traditions the older ones must be "killed" or ridiculed. Thus these are the ancient structures in a modern form.

3) The closer to modernity, the more features of a trickster appear in the image of Santa Claus. It is probable that this falls along the line with the secularisation of the festival and the interests of the merchants in creating an optimistic, merry, comic-book-hero-like image close to children's culture, promoting and personifying shopping and the cult of gifts.

4) Critical irony regarding what is happening to Christmas in the modern culture - we are neither laughing at the festival itself nor at the ancient symbols and values connected to them, actually the laughter indicates our disquietude regarding the developments related to these values - on the contrary to what these developments should have been. Ironic distancing in laughter is a form of resistance where no other resistance is possible.

5) Response to extreme commercialisation, secularisation and stress. The modern Christmas tradition (as opposed to the one at least believed to be inherited from the two to three generations long gone) are characterised by: a) obligatory shopping, sending of a multitude of greetings, complicated preparations - and the continuous resulting pressure involved; b) obtrusive presence of the festive symbols in the public space throughout the Advent; c) aggressive idea of the "correct Christmas" imposed by mass media (within one's family circle, in prosperity, giving gifts to one's family, decorating the house, cooking the meal, visiting relatives) - those people who for some reason would not fit into this framework are subjected to additional pressure (it has been said that the number of suicides is the highest around Christmas); d) desecration, secularisation - the more ancient and traditional religious and family or community rituals (and "even more ancient pagan traditions") are replaced by the "shopping religion". Jokes, including the very "dark" ones, function as means of overcoming the pressure and crises. 
In this context the four video clips described at the outset of the present article could be a response to (or ironic treatment of) Santa's over-mythologisation (demythologisation - destruction of outdated myths in order for those to be replaced by other, newer ones) (Clip 1, see endnote No. 5); over-canonisation of Christmas traditions, making them seem boring and uninteresting (Clip 2, see endnote No. 6); buying expensive and potentially dangerous gifts for Christmas, i.e. commercialisation (Clip 3, see endnote No. 7); extremely obtrusive and uniform "beautiful scenery" during Advent and Christmas (Clip 4, see endnote No. 8).

What could be peculiar about the functioning of these globally known jokes in modern Latvia? The next research topic could be: which jokes of this international offer are chosen and used by the inhabitants of Latvia, which ones do they find funny and which - boring, incomprehensible or unacceptable. Why the choice? One should clearly differentiate particular age, social and professional groups here. According to my humble observations, e.g. among folklore researchers, anthropologists, sociologists (or the retired - as told about at the beginning of the present article) most of the members of the audience knew rather few of the images I demonstrated, but at least some employees of government institutions and office workers knew nearly all of them. This study can also be turned into a more reflexive one - how I myself as a Latvian (and/ or folklore researcher, middle-aged man, city-dweller, computer user, etc.) feel about, choose and comment these jokes. (There is an opinion that the real essence of a person can easily and truly be judged by the jokes told - establishing what are the person's views - and problems...).

Here we reach the topic promised at the beginning of this article: "Why do I dislike Christmas?" That this occasion creates for me more trouble than joy I had noticed a long time ago - already when I was around 20. With each year it became more burdensome to send the numerous greetings - why should I use exactly this occasion to remind my relatives, friends, acquaintances about my existence, and send formal texts or such composed with great difficulty? What makes me do it? I spent much time on the cards, until I gave up completely. Later only those with an e-mail address or enabled reception of non-text messages on cell phones received some greeting from me, i.e. nearly no-one.

The inhabitants of Latvia (similarly to those of other post-socialism states) have undergone several swift changes in the traditions of Christmas celebration (Fig. 18). Under Soviet rule Christmas was celebrated at home: unofficially and

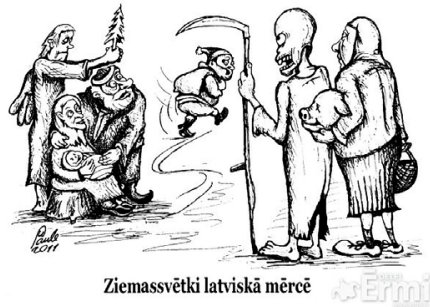

Figure 18. Christmas in "Latvian style". Santa Claus between the Christian and the pagan traditions. (Source: http: / / ermi.delfi.lv / ?actio $n=$ view\&id $=85540 \&$ title $=$ ziemassv etki-latviska-merce-u-saulitis) 
quietly, those clinging to the tradition were elderly people who remembered the festival from the pre-war period. In the time of change around the turn of the 1980s and 1990s (my children were small then, and we formed traditions of our own family, uniting individual childhood experiences), it was difficult to separate Christmas and New Year traditions, ${ }^{28}$ and the children demanded similar gifts for both occasions. It is possible that my "Christmas trauma" was created due to situations when living on a modest scholar's salary I had no money for gifts after paying the bills. I have had to spend the time of Advent in Germany several times, and there I found annoying the intense presence of Christmas symbols, decorations and music in the public space for such a long time - a whole 1/12 of a year. Later, back in my homeland I felt more painfully the "pretension" of Christmas to be the main festival of the turn of the year, though I knew from my childhood that the most important Latvian seasonal festivity is Midsummer. In Germany I experienced the situation where I was alone on Christmas Eve - I could personally feel the psychological risks for an individual left outside the "correct situations" imposed by mass media, unable to spend the holiday with one's family and the closest persons. Therefore, when looking into the history of Christmas traditions I was probably looking for some indications that these traditions are not that general, eternal and self-evident as understood by those around me. Also the interest in the jokes discussed may have been not only purely scholarly, but indirectly related to my problems. Folklore and jokes are the means with the help of which people try to regain a mental balance, compensate for what they lack - or have in abundance - in their real lives.

Jokes are extremely situation-bound and deeply related to different contexts. The material chosen by me and the attempt at its explanation are just a possibility of interpretation. I admit that this very material can be interpreted in a completely different way. And there is another possibility, half-jokingly suggested by my colleague Dace Bula upon seeing my presentation at the Christmas meeting at the Archives of Latvian Folklore: maybe we do not need to study and explain everything, maybe even a scholar has the right to simply enjoy these jokes... So, Merry Christmas!

\section{ACKNOWLEDGEMENTS}

The present article is based on the paper presented at the International Academic Interdisciplinary Conference FROM LANGUAGE TO MIND 3, on 10th-11th September 2009, Tartu, Estonia. Participation of the author at the conference was funded within the framework of the bilateral exchange agreement of the Latvian Academy of Sciences and the Estonian Academy of Sciences. 


\section{NOTES}

1 The main object of my studies and occasionally presented study courses comprises traditional and modern narratives. However, I have had to pay some attention to the Christmas-related topics nearly every year. I have presented public lectures, spoken on the radio and TV. If the lectures happen to be close to the aforementioned festivity, I have discussed this topic with the students (including two such discussions in a multi-ethnic setting in Germany, University of Münster 1997/98 and 2001/02).

2 Similar to the: http://ru.wikipedia.org/wiki/рождественский рассказ, last accessed on 30 March 2012. In my study of Internet folklore I have drawn not only the material, but to a great extent also the research and cultural background information. I am fully aware that references to Wikipedia and similar sources in a scholarly article are "not good style", nevertheless: 1) it offered readily accessible and conveniently arranged basic information on the symbols and traditions I tried to study; this information was - of course! - later checked in more serious printed media; 2 ) in our day Wikipedia's texts form their own secondary tradition - frequently they are the source for articles in mass media, further forming knowledge and views.

3 One version of my presentation, close to shown at the International Academic Interdisciplinary Conference FROM LANGUAGE TO MIND 3 on 10th -11th September 2009, Tartu, Estonia, can be found here: http://failiem.lv/u/cvcggak, last accessed on 30 March 2012.

4 The term is used, e.g., here: http://www.netlore.ru/, (last accessed on 30 March 2012), similarly: http://en.wikipedia.org/wiki/Internet_humor, (last accessed on 30 March 2012), etc. (cf. Brednich 2005: 7-27). Because of the volume of the article here I try to avoid touching upon office lore, Internet jokes and humour theories.

5 See, for instance: http://www.youtube.com/watch?v=sz-xEo2RzHg, (last accessed on 30 March 2012), http://autsch.de/20198/weihnachtsmann_auf_klo/, (last accessed on 30 March 2012). The clip is extremely popular, can be found on different websites. (Usually I indicate its address on YouTube, hoping that this larger site will keep it longer. Besides, it offers some statistical data - though this may be not clearly objective, as the same clip can be uploaded several times with different titles). It must be added that ads can be a very interesting part of Internet communication, if the people consider them interesting and forward (both as files and links). Indeed, it is extremely likely that such clips are consciously developed for the Internet (like beer ads, for example), as their style differs from the official TV commercials.

${ }^{6}$ http://autsch.de/clips/werbung/21228_weihnachtsrocker/, last accessed on 30 March 2012.

7 http://www.youtube.com/watch?v=TXMX_xm7IRo, (last accessed on 30 March 2012), there are other similar jokes along these lines.

8 http://www.youtube.com/watch?v=XZAC4_wPXVI, last accessed on 30 March 2012. The musical material does not appear to be created for the particular clip, as it can also be found elsewhere, belonging to the vast "fart culture", also used in other clips: http://www.youtube.com/watch?v=Vg9eZxpV3VA, last accessed on 30 March 2012, etc.

9 The first versions of the presentation used material from several sites which have changed rather little since my initial study (around 2005): http://joki.oho.lv/default. 
php?grupaid=1, http://www.allfunpix.com/christmas/, http://funpic.hu/en/categories/ santa-x-mas, http://kartinki.smeha.net/novogodnie/, http://www.esche-world.de/ lustigebilder/weihnachten/. All websites last accessed on 30 March 2012.

${ }^{10}$ For instance: http://caricatura.ru/, http://www.delfi.lv/jokes/, last accessed on 30 March 2012.

${ }^{11}$ http://www.netlore.ru/oleni, last accessed on 30 March 2012.

${ }^{12}$ http://en.wikipedia.org/wiki/Christmas_card, last accessed on 30 March 2012.

${ }^{13}$ See on this and the further, as well as the origins of the image which I do not consider necessary to retell here: http://en.wikipedia.org/wiki/Santa_Claus, (last accessed on 30 March 2012), as well as the related local and national entries. One of the most important studies that initiated historical research of Christmas-related traditions is the one by Ingeborg Weber-Kellerman (1978). See also Sirpa Karjalainen (1996).

${ }^{14}$ Entering the name of Santa Claus (or some of his counterparts) in an Internet search engine the top of the list offers pages related to commerce - "the most valuable addresses" (e.g. www.santa.com; www.santa-claus.com (last accessed on 30 March 2012)) are used for Internet stores and travel agents - even if these are made interesting for children. The most recent tradition is to create a "national Santa Claus" postal address and home in every country "with self-respect", see, e.g., http://en.wikipedia.org/wiki/ Veliky_Ustyug, http://ziemassvetkuvecitis.lv/, last accessed on 30 March 2012.

${ }^{15} \mathrm{http}: / /$ www.youtube.com/watch?v=nO4zhi4rd3M, last accessed on 30 March 2012

16 This character is relatively recent - Rudolf the Reindeer first appeared in 1939 when the manager of Chicago supermarket chain Montgomery Ward ordered a Christmas story to be written by a 34-year-old writer Robert L. May. The author wrote it in the form of rhymes to his 4-year-old daughter. The publishing house sold 2.4 million copies of the book and by 1946 already 6 million were sold. The author of this poem used several earlier texts mentioning the names of reindeer pulling Santa's sleigh. http:// en.wikipedia.org/wiki/Rudolph_the_Red-Nosed_Reindeer, last accessed on 30 March 2012.

${ }^{17}$ On the other hand, the written folklore repeatedly presents the calculation how fast Santa should go in order to visit all of the children of the world - to keep the speed he would burn together with his sled in the first seconds of such flight: http://www. daclarke.org/Humour/santa.html, last accessed on 30 March 2012. On the contrary to that another site shows Santa's trip online: http://www.noradsanta.org/, last accessed on 30 March 2012.

$18 \mathrm{http}: / /$ www.youtube.com/watch?v=WRF8mVlDdVc, last accessed on 30 March 2012. Russian folklore, in its turn, deals with the idea that having Snegurochka - a young female companion of Ded Moroz, sometimes called his granddaughter - is good, but reindeer - even better.

19 http://www.youtube.com/watch?v=XXkbDdUgU5A, last accessed on 30 March 2012.

${ }^{20} \mathrm{http}: / /$ www.youtube.com/watch?v=pxMe9ulHt1o, last accessed on 30 March 2012.

${ }^{21} \mathrm{http} / / /$ www.snopes.com/holidays/christmas/cross.asp, last accessed on 30 March 2012.

${ }^{22} \mathrm{http} / / / \mathrm{www}$. snopes.com/holidays/christmas/photos/badsanta.asp, last accessed on 30 March 2012. 
${ }^{23}$ The origin of the theme comes from the correspondence of an editor of The Sun with the 8-year-old Virginia in 1897: http://www.newseum.org/yesvirginia/, last accessed on 30 March 2012. It must be added that the theme used in films, etc.: does Santa really exist - has also become a constant one of Christmas jokes.

${ }^{24}$ For instance: http://www.creepysantaphotos.com/, last accessed on 30 March 2012.

${ }^{25}$ Ded Moroz was introduced in Soviet Russia as an alternative to religiously oriented Santa. Ded Moroz brings gifts for the children during the "Fir-tree holiday" on 31 December, mainly at public events in culture houses, those organised by parents, employers, schools and kindergartens. He is accompanied by a small girl - Snegurochka - and a boy - the New Year. The characters gained popularity after 1935 when a suggestion by Iosif Stalin endorsed the celebration of such a festival. Snegurochka is mentioned in Russian folk-tales (N. Afanasiev's collection, 1855-1863) - an old couple makes a girl of snow, who comes to life, but melts in spring. A. Ostrovsky turned it into a play in 1873, and later - in 1881 - N. Rimsky Korsakov composed an opera. For a long time (following Stalin's order), the costume of Ded Moroz was either blue or white, emphasising the difference from the "capitalist" Santa, but gradually the colour red as an important part of the soviet culture was also accepted for his costume. See also http://en.wikipedia.org/wiki/Ded_Moroz, (last accessed on 30 March 2012), and the related entries - it is interesting to compare different language (country) versions regarding the history of these characters.

${ }^{26}$ See also Bernd Brunner (2011); Walter Pötzl (1999: 51-55), and http://de.wikipedia. org/wiki/Weihnachtsbaum, last accessed on 30 March 2012.

${ }^{27}$ If the Internet encyclopaedias can be trusted at all the oldest mention of snowman is found in the works of Shakespeare, but later, for some time, it is not mentioned and depicted. The character gains popularity in connection with the winter landscape in the children books of the 18th century. The snowman by the Christmas tree and on greeting cards was first depicted around 1900. See also: http://de.wikipedia.org/wiki/ Schneemann, last accessed on 30 March 2012.

${ }^{28}$ According to my observations in the beginning of the 1990s there were fireworks in Latvia on both Christmas and New Year's Eve. Even now quite impressive fireworks in Riga are fired at 11 p.m. and not at midnight according to the Latvian time; this means that quite a large number of inhabitants are still watching the Russian TV channels and have closer connections with that country.

\section{REFERENCES}

Brednich, Rolf Wilhelm 2005. www.worldwidewitz.com: Humor im Cyberspace. Freiburg im Bresgau: Herder.

Brunner, Bernd 2011. Die Erfindung des Weihnachtsbaums. Berlin: Insel Verlag.

Karjalainen, Sirpa 1996. The Finnish Santa Claus in Search of a Home. ARV. Nordic Yearbook of Folklore, Vol. 52, pp. 135-144.

Pötzl, Walter 1999. Brauchtum. Von der Martinsgans zum Leonhardiritt, von der Wiege bis zur Bahre. Augsburg: Landratsamt.

Weber-Kellerman, Ingeborg 1978. Das Weihnachtsfest. Eine Kultur- und Sozialgeschichte der Weihnachtszeit. Frankfurt am Main \& Luzern: Bucher. 